\title{
Drogas na Escola: análise das vozes sociais em jogo
}

\author{
João Paulo Pereira Barros' \\ Veriana de Fátima Rodrigues Colaço' \\ 'Universidade Federal do Ceará (UFC), Fortaleza/CE - Brasil
}

RESUMO - Drogas na Escola: análise das vozes sociais em jogo. $O$ artigo visa analisar vozes sociais em jogo na produção de sentidos sobre drogas entre adolescentes, em um grupo de discussão sobre saúde no contexto escolar. Ancorando-se na Saúde Coletiva e nos legados de Vigotski e Bakhtin sobre os processos de significação, são utilizados dados de uma pesquisa de mestrado operacionalizada por observações-participantes e pela formação de um grupo de discussão em uma escola pública de Fortaleza/CE. Os resultados apontam tensões entre vozes sociais nos posicionamentos dos adolescentes sobre drogas, destacando a força com que vozes alusivas a um discurso de guerra às drogas e a estratégias proibicionistas ainda circulam no contexto escolar, em que pese a emergência da perspectiva de redução de danos.

Palavras-chave: Adolescência. Drogas. Escola.

ABSTRACT - Drugs in School: analysis of social voices. This article aims to analyze social voices at play in the production of meanings about drugs among adolescents in a group discussion on health in the school context. Based on Public Health and the legacy of Vigotski e Bakhtin on the processes of signification, data for a Master thesis, developed by means of participant observation and a discussion group in a public school in Fortaleza/CE, are used. The results indicate tensions between social voices on the claims of adolescents about drugs, highlighting the strength with which a speech alluding to the war on drugs and prohibitionist strategies voices still circulate in the school context, despite the emergence of the harm reduction perspective.

Keywords: Adolescence. Drugs. School.

Educação \& Realidade, Porto Alegre, v. 40, n. 1, p. 253-273, jan./mar. 2015.

253

Disponível em: <http://www.ufrgs.br/edu_realidade> 
Este artigo se configura como uma aposta na intercessão entre os campos da Educação e da saúde, tendo como objetivo compartilhar resultados de uma pesquisa de mestrado, ligada ao Programa de Pós-Graduação em Psicologia da Universidade Federal do Ceará (UFC), que teve como intuito principal compreender o caráter mediador das interações de um grupo de discussão sobre saúde, realizado com adolescentes de uma escola pública de Fortaleza, nos posicionamentos dos participantes. Neste texto, especificamente, objetiva-se enfocar e discutir os sentidos que foram produzidos pelos participantes acerca do tema drogasum dos assuntos debatidos no grupo - e as vozes sociais em jogo nesses processos de produção. Esse enfoque se justifica pelo fato de ser este um tema que vem suscitando grandes inquietações entre os atores escolares e entre os meios de comunicação, cotidianamente.

Teoricamente, a referida pesquisa de mestrado esteve ancorada no campo da Saúde Coletiva, ressaltando a produção social dos processos de saúde, doença e cuidado. Além disso, para dar conta da compreensão dos processos de significação atinentes às interações entre os participantes do grupo de discussão, a pesquisa buscou referência na Psicologia Histórico-Cultural, criada por Vigotski, e na Filosofia da Linguagem delineada por Bakhtin. Sobre alguns aspectos que aproximam Vigotski e Bakhtin, ambos construíram suas perspectivas sob a inspiração do materialismo histórico-dialético, estabelecendo o plano culturalmente constituído da sociabilidade humana como ponto fulcral para a tematização da consciência. Ademais, tanto um quanto o outro, apesar de em muitos momentos versarem sobre temas diferentes, contrapuseram-se a correntes objetivistas e subjetivistas, seja no âmbito da Psicologia, no caso de Vigotski, seja no âmbito dos estudos da linguagem, no caso de Bakhtin. Ao problematizarem perspectivas objetivistas e subjetivistas ao longo da construção de suas ideias, Vigotski e Bakhtin deixavam clara a tentativa de operar rupturas com a dicotomia social/ individual, lançando mão do método dialético. Em decorrência, ambos os autores se notabilizam em seus campos de interesse por situarem as relações sociais como constituintes do funcionamento humano e como princípio explicativo deste funcionamento.

Mas, apesar de muitos pontos de aproximação, cumpre registrar que há também diferenças entre essas perspectivas. Por exemplo, a unidade de análise dos estudos de Bakhtin era o enunciado, enquanto que o significado da palavra era a unidade de análise das investigações vigotskianas sobre a relação pensamento-linguagem. Ademais, Freitas (1996, p. 159) aponta diferenças quanto ao enfoque em determinadas temáticas:

Vygotsky, ao reformular a psicologia numa perspectiva marxista, pouco se deteve na discussão de temas como: lutas de classes, ideologia, relações infra-super-estrutura, instituições sociais. Foi Bakhtin quem se preocupou especialmente com essas questões. Daí ter situado a fala 
corrente num contexto mais amplo, identificando várias expressões ideológicas que interligam e se multideterminam. Vygotsky [interessado em como se constroem as funções psicológicas tipicamente humanas] situou a fala corrente num contexto mais restrito: o das relações imediatas entre os indivíduos, porém sem perder a dimensão mais ampla do meio cultural e da história.

Em que pesem essas peculiaridades nas perspectivas vigotskiana e bakhtiniana, neste artigo se apostou na possibilidade de que tal interlocução seria profícua para lançar luzes sobre os processos de significação. Assim, com base no diálogo entre esses dois autores, os sentidos sobre os temas trabalhados no grupo de discussão, em meio às atividades discursivas em que estiveram envolvidos os participantes, foram concebidos como acontecimentos semânticos particulares, constituídos, dialogicamente, nas relações sociais, a partir da articulação de diferentes vozes sociais que atravessavam os enunciados dos participantes (Vigotski, 2001; Bakhtin, 2002).

Com efeito, tomando por base os dados produzidos pela pesquisa supramencionada, este artigo buscará dar conta dessas duas questões específicas: que sentidos foram produzidos sobre o tema drogas em meio às interações daquele grupo de discussão sobre saúde? Que vozes sociais estiveram em jogo nesse processo de produção de sentidos sobre esse tema?

Uma variedade de estudos indica a elevação do consumo precoce e abusivo de drogas lícitas ou ilícitas no Brasil (BEMFAM, 1992; Paulilo; Jeolás, 2000; Souza; Monteiro, 2011). Assim, abordagens preventivas frente ao uso de drogas têm sido amplamente consideradas, por especialistas e por significativa parcela da população, como necessidade mundial e premente.

A estratégia de minorar o uso indevido de drogas ganhou evidência a partir da década de 70 do século XX. Naquele período, a Organização das Nações Unidas para a Educação, a Ciência e a Cultura (Unesco) passou a salientar o papel da escola como espaço da maior importância para a realização de uma abordagem preventiva ao abuso de drogas (Moreira; Silveira; Andreoli, 2006). Soares e Jacobi (2000) destacam a relevância da escola como local privilegiado para trabalhar prevenção às drogas pela possibilidade de acesso aos jovens e por seu lugar socialmente legitimado como instituição formadora de crianças e adolescentes.

Não obstante, são múltiplos os modelos de intervenção na instituição escolar ante o uso abusivo de drogas. Moreira, Silveira e Andreoli (2006) citam, por exemplo, três tipos de estratégias preventivas: 1) diminuição da oferta de substâncias, envolvendo, sobretudo, ações de repressão; 2) redução da demanda por parte do usuário, voltando-se para intervenções pedagógicas; e 3) influência sobre as circunstâncias favorecedoras da oferta e da procura, referindo-se a intervenções com o 
intuito de alterar o contexto onde a saúde se constitui. Dessa forma, as intervenções no cotidiano escolar abrangem estratégias de redução de demanda e/ou ações na intercessão entre oferta e demanda.

Mülller, Paul e Santos (2008, p. 610), assim como Moreira, Silveira e Andreoli (2006), ressaltam duas das principais posturas pelas quais se abordam o uso e o abuso de substâncias psicoativas no contexto escolar:

[...] a primeira que estimula a proibição, pela diminuição da oferta, com informações que se caracterizam pelo apelo moral e produção de medos, persuadindo as pessoas à abstinência; a segunda é a redução de danos, com propostas como: oferecimento de alternativas, educação para a saúde e modificações das condições de ensino.

Na primeira abordagem, historicamente mais tradicional, a maior concentração de esforços se dá na transmissão de informações proibicionistas, com foco na abstinência, seguindo, em geral, um modelo educativo de aprendizado passivo. Já a redução de danos é uma política de saúde cujo intuito é reduzir os prejuízos biológicos, sociais e econômicos do uso de drogas, a partir de cinco princípios: 1) contraposição aos modelos moral, criminal e de doença; 2) crítica à proposta da abstinência como discurso único no tocante à prevenção ao uso abusivo de substâncias psicoativas, aceitando, portanto, alternativas que minimizem os danos, uma vez que o foco deixa de ser a droga em si, mas a qualidade de vida do indivíduo em sua integralidade; 3 ) defesa dos direitos do dependente; 4) promoção de acesso a serviços que acolhem usuários de forma mais tolerante, não exigindo a abstinência total como condição prévia para a aceitação ou permanência do usuário; 5) adoção de pragmatismo empático versus idealismo moralista.

Ao publicar a Política Nacional sobre Drogas, em 2005, o Ministério da Saúde adotou a abordagem de redução de danos como estratégia de prevenção ao uso abusivo de substância psicoativa, articulando-a ao conceito de promoção de saúde e à ampliação do conceito de saúde, enfocando sua multidimensionalidade (Müller; Paul; Santos, 2008)

Ao tratar das orientações gerais para prevenir o uso abusivo de drogas, tal política reafirma o papel primordial da escola, ao apontar que a efetiva prevenção resulta do comprometimento conjunto de diferentes segmentos sociais e órgãos governamentais da sociedade brasileira, de modo a multiplicar ações que incentivem a socialização de conhecimentos sobre drogas, o protagonismo juvenil e a produção de saúde. A participação da escola também figura entre as diretrizes dessa política, na medida em que, por exemplo, propõe-se a capacitação continuada de educadores e a inclusão de conteúdos referentes ao uso indevido de drogas, no ensino básico e superior (Brasil, 2005). 


\section{Metodologia}

\section{Tipo de Pesquisa}

A pesquisa de mestrado, de cuja proposta foi recortada a problemática levantada neste artigo, consistiu numa pesquisa-intervenção cuja etapa empírica foi executada de agosto a novembro de 2009. A pesquisa-intervenção tem sido abordada de diversos modos, principalmente nos últimos anos, como uma forma de aliar produção de conhecimento e intervenção social. A propósito, Aguiar e Rocha (2007) definem a pesquisa-intervenção como uma investigação de caráter participativo que almeja a intervenção na produção de micropolíticas de transformação social. Desse modo, pesquisar e ao mesmo tempo intervir significou, no contexto dessa pesquisa, "criar dispositivos de análise coletiva" (Lourau, 1993, p. 30).

Em meio às múltiplas entradas já realizadas neste tema, alguns pontos são recorrentemente ressaltados como característicos da pesquisa-intervenção. Dentre eles, estão: 1) o pressuposto de que a construção de conhecimento é compartilhada e sócio-historicamente erigida; 2) a desconstrução das dicotomias ciência/política, sujeito/pesquisador, teoria/prática; 3 ) a premissa de que a relação entre o pesquisador e os demais participantes da pesquisa é condição para a investigação, e não um empecilho à sua realização.

\section{Lócus da Pesquisa}

O lócus da pesquisa-intervenção foi uma escola pública de ensino fundamental e médio, localizada na periferia de Fortaleza. Na escolha da escola, foram considerados os seguintes critérios: a instituição escolar deveria desenvolver trabalhos com jovens à época da realização da pesquisa; discutir questões relacionadas à saúde - ou manifestar interesse em fazê-lo com jovens - e demonstrar disponibilidade e interesse de ser o local de realização da investigação.

\section{Participantes da Pesquisa}

O grupo de discussão sobre saúde formado na escola, por ocasião da pesquisa-intervenção, contou com onze participantes - dez estudantes de 15 a 17 anos, sendo 3 do sexo masculino e 7 do sexo feminino, e um professor da instituição. No tocante ao número de integrantes, o ponto de partida assumido foi de que, num grupo de 10 a 15 pessoas, tanto a dinâmica de interlocução entre os partícipes seria mais efetiva, quanto o uso de técnicas para facilitar as interações se tornaria mais eficiente, além de que se teriam condições de viabilizar a intervenção mesmo com/por possíveis flutuações na frequência ou por eventuais desistências. 
Como critério para a formação do grupo, ponderou-se que seria relevante que os participantes, estudantes ou profissionais da instituição, fossem pessoas que: (1) se interessassem em discutir processos de saúde/doença no cotidiano em que vivem e (2) tivessem disponibilidade de participar de todo o processo. Considerando esses critérios, foi estendido o convite à participação no grupo também aos professores, supervisores e diretores da escola. Após o convite, um professor se disponibilizou a participar. Tal fato trouxe algumas incertezas: ao fazer essa opção, se assumiu o risco de que a presença de um professor nos encontros, por si só, seria capaz de mudar sua configuração, dada sua posição social diferencial em relação aos alunos. Mas, por outro lado, poderia proporcionar mais diversidade de sentidos e possibilidades de negociação de posicionamentos no grupo, o que, para a intervenção, seria um ponto positivo.

Cabe salientar ainda que a pesquisa foi conduzida dentro de padrões éticos exigidos pela Comissão Nacional de Ética em Pesquisa/ Conselho Nacional de Saúde/Ministério da Saúde (CONEP/CNS/MS) no que diz respeito à pesquisa empírica com seres humanos. Tanto os responsáveis legais dos estudantes quanto o professor que participou do estudo firmaram seu consentimento para a realização da pesquisa a partir de um Termo de Consentimento Livre e Esclarecido, previamente aprovado pelo Comitê de Ética em Pesquisa da Universidade Federal do Ceará.

A propósito, em conformidade com os padrões exigidos para pesquisas com seres humanos, nomes fictícios foram criados para referência aos participantes ao longo da pesquisa e aos seus respectivos depoimentos.

\section{Procedimentos de Geração de Dados}

De agosto a novembro de 2009, a pesquisa-intervenção se efetivou a partir de observações-participantes do cotidiano daquela instituição escolar, registradas a partir de diários de campo, e da formação de um grupo de discussão sobre saúde com os 11 participantes supramencionados, operacionalizado a partir da metodologia de oficinas. O grupo de discussão se realizou por meio de 09 oficinas sobre os seguintes temas, escolhidos pelos participantes: o que é saúde, saúde mental, transtornos alimentares, drogas e sexualidade. O tema drogas, sobre o qual versará especificamente o presente artigo, foi trabalhado na quinta e na sétima oficina.

Cada oficina teve duração de $01 \mathrm{~h} 30 \mathrm{~min}$, foi facilitada pelo pesquisador e registrada a partir de diários de campo e da videogravação das interações entre os participantes, realizada por uma pesquisadora auxiliar, à época estudante do mestrado em psicologia da Universidade Federal do Ceará (UFC). Em todas as oficinas, foi realizado um momento de acolhida, seguido de sensibilização para a temática da oficina, seja 
por meio de letra de música, dramatizações, colagens, notícias de jornal, seja a partir de outra técnica de trabalho grupal. Após esses dois momentos, adentrava-se na discussão do tema a ser especificamente trabalhado, geralmente a partir de questões suscitadas pelo momento de sensibilização. Por fim, era realizada uma avaliação do encontro, mediante a qual se reiterava a data do encontro seguinte e sua respectiva temática a ser discutida.

Embora todas as oficinas tenham seguido esse percurso, as definições dos recursos metodológicos a serem utilizados em cada oficina ocorreram mediante a inserção no contexto da escola e no decurso da intervenção. Assim, cada encontro funcionou "[...] como orientador do modus operandi do próximo” (Menezes; Arcoverde; Libardi, 2008, p. 205).

\section{Análise dos Dados}

A unidade de análise da investigação foi a atividade discursiva (Coll; Onrubia, 1998) do grupo de discussão, que correspondeu aos processos interacionais semioticamente mediados - como as interlocuções e as demais atividades realizadas em grupo. Ao trabalhar com tal unidade, partimos do pressuposto, conforme a perspectiva bakhtiniana, de que o discurso inclui os enunciados e suas condições de produção, abarcando elementos linguísticos e extralinguísticos que participam da construção de sentidos num determinado contexto.

As atividades discursivas foram examinadas a partir de uma análise microgenética, que se trata da "análise minuciosa de um processo, de modo a configurar sua gênese social” (Góes, 2000, p. 9). Sua aplicação “[...] requer a atenção a detalhes e o recorte de episódios interativos, sendo o exame orientado para o funcionamento de sujeitos focais, as relações intersubjetivas e as condições sociais da situação, resultando num relato minucioso dos acontecimentos" (Góes, 2000, p. 9).

A seguir, os resultados e discussões propiciados pelas análises microgenéticas das interações nas quais sentidos eram construídos pelos participantes acerca do tema drogas, tendo em vista o propósito específico deste artigo.

\section{Resultados e Discussão}

O tema drogas veio a lume na quinta e na sétima oficina que compôs o grupo de discussão formado na escola-lócus da pesquisa-intervenção.

Na quinta oficina, foi proposto aos participantes que, antes do debate propriamente dito, eles elaborassem uma dramatização que abordasse o tema em questão. Foi assim que quatro adolescentes elaboraram e encenaram a peça intitulada Certo ou Errado. O enredo elaborado contou a história de uma jovem, interpretada por Camila, que passava

Educação \& Realidade, Porto Alegre, v. 40, n. 1, p. 253-273, jan./mar. 2015.

259

Disponível em: <http://www.ufrgs.br/edu_realidade> 
por conflitos com sua mãe, encenada por Renata. Na história, a jovem se rebelou contra as ordens da mãe e foi a uma festa ao encontro dos amigos da escola. Na festa, a personagem vivenciou intensos dilemas provocados pelas disputas internas entre a voz do bem - interpretada por Laura - e a voz do mal-encenada por Lia, em torno do uso de drogas na festa. A seguir, segue a transcrição da dramatização:

Laura: O nome da peça é "certo ou errado"

Pesquisador: "Certo ou errado"?

(Inicia-se a dramatização. Toca o telefone celular da protagonista, interpretada por Camila).

Camila: Alô. Oi, tudo bom? Vai ter festa? Aonde? Ah, eu vou, eu vou. Quem é que vai? A ele vai, né, vai levar muita droga da boa. É, pois eu vou. Só que eu tenho que pedir pra minha mãe, num sei se ela vai permitir. Tá certo. Ta. Tchau. Mais tarde eu vou viu, pode contar comigo lá, guarda a minha lá. Até mais tarde. Tchau.

Renata: Quem era?

Camila: Era uma menina lá da sala, mãe.

Renata: O que é que ela queria?

Camila: Pediu pra mim fazer um trabalho com ela.

Renata: Trabalho de quê?

Camila: Um trabalho, mãe, da escola! (fala irritada, expressando impa-

ciência da jovem com as perguntas da mãe)

Renata: Me ajudar a fazer as coisas antes de ir!

Camila: Não mãe. Eu chego, eu faço tudo dentro de casa. Meus irmãos não me ajudam. Só precisa de mim, o pessoal só chama eu pra fazer as coisas, num me dá nada.

Renata: É, mas eu também tô cansada de fazer as coisas. Vá lavar as louças.

Camila:Eu num vou fazer nada, não. Eu vou ficar aqui assistindo televisão o dia todo.

Renata: Pois você não vai sair de casa hoje, não!

Camila: Eu vou. Ah, mãe, tem festa hoje, eu vou, num quero saber, não. Eu vou!

Renata: Vai não!

Camila: Eu vou!

Renata: Bora ver se você vai...

(Lia entra em cena, fazendo as vezes de narradora da dramatização)

Lia: E assim chega de noite (anuncia, no papel de narradora também).

Camila:Ela vai ver que eu vou. (se levanta e se arruma) Aí ele vai ver, deixa eu me arrumar.

Renata: Camila, pro quarto dormir!

Camila: Já tô indo, vou já....

Renata: Tá, eu vou me deitar.

Camila: Tchau.

(Camila se levanta da cadeira onde se arrumava e sai de casa escondida da mãe, rumo à festa. Chega à festa e começa a conversar com os amigos) Camila: E aí, o que é que tem pra mim? Oba! (Começa a cheirar um pô na cadeira, simulando uso de substância psicoativa)

(Lia se aproxima de Camila, como se fosse uma voz imaginária, e incentiva a garota a continuar usando drogas)

Lia: Isso garota! O pó, o pó!! 
Laura também se aproxima de Camila e de Lia, como se fosse uma outra voz imaginária. Enquanto Camila encontra-se sentada na cadeira, usando drogas, Lia fica de pé do lado direito de Camila, enquanto Laura fica do lado oposto, também de pé).

Laura: Não, não faça isso não. Isso vai lhe causar muitos danos!

(Ao mesmo tempo, Lia, como se fosse uma voz, incentiva Camila, e Laura, como se fosse outra voz, tenta desestimulá-la quanto ao uso de drogas)

Laura: Não é certo, Não faça isso!

Camila: Sai, sai (empurra Laura, afastando-a, e intensifica o uso de drogas, ainda na cadeira)

Lia: Isso, garota!! (após o afastamento da voz do bem) Todo, todo, não para!! (referindo-se ao pó) Isso, você tá certa! Você tem que ir na minha intuição!

Laura: Não escute ela! (fala de longe, dirigindo-se à Camila)

Lia: Melhor você me escutar (dirigindo-se à Camila, imediatamente em seguida).

Camila: Sai daqui! (dirigindo-se à voz encenada por Laura)

Laura: E seu futuro, como fica?

Camila: Não tenho futuro. Minha mãe não quer saber de mim, meu pai... Laura: Ela só quer o seu melhor! (interrompe Camila)

(Camila continua)

Camila: ... pra abusar de mim. Meus irmãos também. Aqui é a solução pros meus problemas (referindo-se às drogas).

Lia: Não escute ela (dirigindo-se à Camila e referindo-se à Laura). Mais, mais!! (Camila intensifica o gesto que indica que está cheirando um pó na cadeira)

(continua a conversa entre Camila e a voz protagonizada por Laura)

Laura: Mas têm outros meios pra resolver seus problemas, esse não é o único meio!

Camila: Aqui a solução é mais rápida!

Lia: a sua solução agora é a droga. Não escute ela. Não escute ela!

Laura: Vá pra casa que é melhor. Saia dessa vida.

(Imediatamente à ordem da voz de Laura, Camila para de usar drogas e se levanta da cadeira)

Camila: Sai!! (grita e empurra Lia)

(Cambaleante, a protagonista se movimenta para outra parte da sala, como se estivesse saindo da festa e voltando pra casa, onde sua mãe a espera, sentada em uma cadeira)

Renata: Camila, de onde é que você vem desse jeito, essa hora? Eu disse que não era pra você sair de casa hoje!

(Camila senta em outra cadeira)

Camila: Mãe, eu não tô me sentindo bem, não, mãe! (fala com voz trêmula, como se estivesse chorando)

Renata: (sentada perto de Camila) O que foi que você fez naquela festa? (muda o tom de voz, num tom mais compreensivo)

Camila: Me deram muita coisa pra usar, eu tô tonta, não tô passando bem! (ainda com fala trêmula, como se estivesse chorando)

Renata: Vamos pro médico agora!

(Mãe e filha se levantam e saem de casa).

Laura: Pronto!

(encerra-se a dramatização)

(Risos das participantes) 
O cenário da dramatização, as tarefas domésticas que a jovem desempenhava, os conteúdos de sua discussão com sua mãe e a atitudes de cada personagem davam testemunho do grupo social de referência para os jovens. Decorre do princípio dialógico que “[...] o discurso (falado ou escrito) envolve necessariamente múltiplos sujeitos - falantes e ouvintes, locutores e interlocutores, ou escritores e leitores -, que orientam e definem os rumos da produção discursiva” (Colaço, 2004, p. 334). Então, concebendo o dialogismo como condição do sentido do discurso e também como o espaço interacional entre o $\mathrm{eu}$ e o $t u$ no enunciado, é presumível que as palavras proferidas pela protagonista da história trouxessem consigo as perspectivas de uma série de outros interlocutores virtuais.

Além disso, aquele processo enunciativo, eminentemente dialógico, dá pistas do caráter histórico e ideológico da construção subjetiva. Constituído da e pela linguagem, o sujeito é permeado por vozes heterogêneas. Tais vozes também heterogeneamente constituem o tecido social, sendo reveladas pelos diferentes planos que as interações comunicacionais comportam (Costa, 2007; Bakhtin, 2002). Ora, o que ocorre na dramatização não é senão um escancarar desse processo. O dilema vivido pela personagem principal na situação do uso de drogas possibilita observar que ela era atravessada por vozes que se encontravam em franco embate - as vozes do bem e as vozes do mal, conforme nomearam os participantes, presentificando vieses maniqueístas e moralizadores que situam o usuário de drogas no lado obscuro de uma suposta linha social que divide os usuários (maus) e os não usuários (bons).

Após a dramatização, foram discutidos seu processo de elaboração e alguns aspectos que mais se destacaram na trama:

Pesquisador: Eu queria começar, assim, a discussão perguntando como é que foi montar, como é que foi que vocês chegaram à essa ideia que foi a peça?

Lia: Ah, surgiu de repente.

Camila: Foi rápido.

Pesquisador: Foi rápido? Mas como foi, assim, vocês tiveram outras ideias? Lia: A gente puxou mais pro lado da realidade, do que acontece realmente. A mãe, a filha que não obedece, que não tá nem aí, e as influências (faz sinal de aspas com as mãos)...

Laura: As amizades (fala enquanto Lia também está falando).

Lia: ... tem gente que diz "não faz isso", tem gente que diz "faz isso"... as influências que...

Renata: Aí, muitas vezes a pessoa vai pelo lado ruim, né, usa droga, aí passa mal, tem overdose, essas coisas.

Laura: E no final das contas, a pessoa sempre, ela não quer escutar a mãe, né, mas, como a gente falou na peça, sempre quem ajuda é a mãe, mesmo o filho estando lá drogado, acabado, ali no fim, mas sempre quem tá ali é a mãe. A mãe não quer, não quer, luta pro filho não ir, mas na hora difícil os amigos todos somem, mesmo aquele que tá na boa, ele some, fica sempre a mãe. 
Pesquisador: Então, aquela cena daqui do canto que a personagem que tava usando drogas, né, ela tava interagindo ali com as ideias de não usar e com as ideias de usar. Então eram imaginárias, não eram pessoas reais que estavam ali?

Laura: A voz do mal é como se fosse as influências...né...as amizades...E a voz do bem, né, como se fosse a família.

Pesquisador: Mas as amizades sempre levam para esse caminho? Não têm amizades que podem levar pro contrário também não? Camila: Tem, mas a maioria quer levar pro caminho errado.

Pesquisador: Que aí isso foi uma coisa que vocês já viram acontecer em lugares que você foi? Vocês também já presenciaram situações parecidas com essa que tava sendo encenada aqui?

Lia: Já vi. Lá perto de casa é só o que tem..

[...]

Pesquisador: No caso da peça de vocês, o que tava influenciando, ali, pra o uso?

Laura: Acho que era a busca de felicidade, né (olha pra Camila).

Camila: Eu acho que era, assim, por causa... de acordo com a peça... é... a personagem principal, no caso eu, que era, tipo, a solução pros problemas. Porque, também..

Pesquisador: Mas que tipo de problemas tavam acontecendo com ela, ali? Camila: Questão, assim, social, né, social não, dentro de casa, familiar. Porque dentro de casa... eu presenciei, próximo da minha casa, que a mãe fica falando, não... que fica falando dos amigos: - "Ah porque eu não gosto daquele menino. Ele usa droga, não sei o quê. Vai bem te chamar também". Acho que é só pra demonstrar.: - (reproduz o pensamento de alguém que está sendo influenciado pelo amigo a usar droga) "Se ele usa eu vou usar também, só pra ver o que ele tá fazendo"...

Pesquisador: Entendi.

Laura: Tipo uma revolta, né?

Camila: É, uma revolta. A gente quer defender os amigo da gente que usa, mas acaba entrando na mesma coisa que ele.

Laura: Mas eu acho assim, se você sabe que você é fácil pra influenciar, você fugir daquela tentação, daquilo, assim, se você tem aquela sua opinião formada: - "porque eu não quero, acabou". Mas se você sabe que tem aquela capacidade... se alguém te influenciar e mudar de opinião muito rápido, é melhor você fugir dessa coisa. Eu acho também se o pai fala: "meu filho..." Porque ele conhece o filho que tem, né...: - "não vá, não". Porque eu acho que ele deve saber rapidinho influenciado...

Lia: O filho se sente pressionado.

Camila: Pra entrar num grupo, né, vamos supor, tem cinco pessoas, quatro usa, então: - "Diabo é isso, mah, olha aí o cara não usa nada".

Laura: Aí se a pessoa tem a opinião dela, tipo: - "Não, eu não quero usar, mas estou sendo do grupo, eu me aceito assim, como eu aceito vocês usando, ou então acabou, eu tenho minha opinião própria" (reproduz o diálogo de alguém que não se deixa influenciar pelos outros).

No tocante à circulação de sentidos sobre drogas, pelo menos três pontos dessa discussão sobre a formatação da peça merecem realce: 1) no enredo construído pelas participantes e nas justificativas dadas para tal construção, ecoavam as vozes sociais que reiteram a associação entre juventude e desobediência como o retrato da realidade; 2) as 
buscas por solução para os problemas e a influência dos pares surgiam na dramatização e na discussão posterior como os principais aspectos que levariam os jovens ao uso de drogas; 3) foram dados sentidos negativos à influência dos pares, a qual, na dramatização, pôde ser representada pela voz do mal. Pelo posicionamento das participantes, essa má influência dos pares se contraporia ao apoio que a família ofereceria ao jovem. Esse contraponto - família/voz do bem versus influência dos pares/voz do mal - fica realçado no desenrolar da peça, sendo plausível considerá-lo como indício de tensões entre o discurso adulto sobre o risco das socializações fora da família e as contestações a esse discurso.

De grande riqueza foi também a discussão delineada sobre os sentidos construídos acerca de como esse tema se apresenta na realidade da escola. O episódio a seguir traz parte desta discussão e nele podemos notar que essas questões, como o uso de maconha, fazem parte do cotidiano escolar, segundo os participantes.

Pesquisador: Como é que é trabalhada essa questão das drogas aqui na escola? Aqui vocês também presenciam situações de uso ou abuso de drogas.

Camila: No ano passado rolava.

Laura: Tem horas... no banheiro dos meninos se você passar na frente você sente um cheiro horrível de maconha, quem entra sente um cheiro muito forte, cigarro apagado no chão, essas coisas assim.

Lia: Eu já ouvi falar também dos meninos quando ia pro banheiro... os meninos, assim, mais... vão só pra usar maconha.

Camila: Foi, no ano passado, no ano passado, tinha aluno do oitavo ano que tinha usado maconha dentro do banheiro.

Laura: E até pessoas que... vendem dentro do colégio.

Renata: Já vem (interrompe Laura)... já vem drogada pro colégio.

Laura: Ou vendem no colégio.

Lia: Eu já percebi, já.

Laura: Tinha um menino da minha sala que ele vinha, foi até expulso do colégio, ele vinha com o olho vermelho, não falava coisa com coisa.

Chama a atenção o fato de que, ao se lançar o tema do uso de drogas entre os participantes, eles associem tal questão ao uso de drogas ilícitas, como se a questão do uso e dos efeitos de substâncias lícitas, como o tabaco e o álcool, no contexto social e na escola, não tivesse visibilidade na discussão sobre drogas também.

Por seu turno, na sétima oficina, uma nova discussão sobre drogas ocorreu, dessa vez mediante uma atividade de perguntas e respostas elaborada por Lia e Renata. A seguir, um episódio que girou em torno de uma das perguntas formuladas pelas adolescentes, acerca do assunto drogas:

(Mariana pega a caixa com as perguntas, retira um papel com uma pergunta elaborada por Lia e Renata. Lê em voz alta a pergunta)

Mariana: "Marta tem 16 anos e foi convidada para uma festa de casamento. Tinha bebida na festa. Ela nunca havia bebido muito, mas, como estava quente, tomou uns quatro ou cinco deles. A frase 'evite o primeiro gole' 
serve para todos ou apenas para aqueles que são viciados, que estão em fase de tratamento?".

Pesquisador: O que vocês acham, gente?

Mariana: Rapaz, eu acho que é pra todos. Porque, tipo assim, se você não conhece é melhor você não conhecer pra depois você não ter vontade de repetir, né? Aí é melhor prevenir do que remediar. Num é verdade? Pronto, falei.

Pesquisador: Sobre o tema drogas, né. O que é que vocês acham aí dessa questão? (dirigindo-me aos demais participantes)

Lia: Foi como ela disse (referindo-se à Mariana), eu acho que a gente tem que evitar o primeiro gole sim, porque se não vai ficar viciado, querer tomar mais. Tem que evitar a primeira mesmo.

Pesquisador: Mas toda pessoa que toma o primeiro gole se torna um viciado?

Lia: Não.

Mariana: Não.

Renata: Eu acho que não.

(Lia, Mariana e Renata respondem ao mesmo tempo)

Mariana: Não, mas é melhor prevenir.

Renata: Vai que vicia.

Mariana: É, você não sabe, né.

Lia: Nem tanto viciar, mas fica tomando, aí vai que aumenta... a vontade. É melhor evitar.

Nesse episódio, ficou novamente evidente quão forte era o discurso preventivo com foco na abstinência entre os participantes do grupo. Exemplo disso foi a potência que enunciados como Evite o primeiro gole! ganhavam nas atividades discursivas, reafirmando os sentidos que se sobressaíram nas interações durante a oficina sobre drogas. Naquelas interações, levando em conta a dramatização e as discussões que a sucederam, ficou perceptível que os participantes referendavam o ponto de vista - bastante corrente, por sinal - de que o jovem é o responsável principal por sua entrada no (sub)mundo das drogas, já que há muitas ações que visam a informá-lo e adverti-lo quanto aos riscos dessa entrada.

Uma questão curiosa endossava como aqueles adolescentes se apropriavam do discurso da prevenção às drogas. Mesmo reconhecendo os problemas e dificuldades do dia a dia que podem favorecer o uso de drogas, as alternativas de combate a esse uso, que aparecem no discurso dos jovens, não acenavam para o enfrentamento destes problemas. As alternativas passavam pela modelação das condutas dos indivíduos, como ficava explícito em enunciados como Evite o primeiro gole e É melhor prevenir do que remediar.

A posição enunciativa dos participantes frente ao tema em destaque revelava suas marcas culturais, pois se relacionam ao modo como a questão das drogas tem sido vista na sociedade, tradicionalmente. Afinal, “[...] todo enunciado está habitado da significação histórica que seu uso condensou" (Costa, 2007, p. 50). À luz de Vigotski e Bakhtin, a composição de sentidos, visto que não é uma operação solitária do

Educação \& Realidade, Porto Alegre, v. 40, n. 1, p. 253-273, jan./mar. 2015.

265

Disponível em: <http://www.ufrgs.br/edu_realidade> 
indivíduo, está imbricada a condições de produção que tanto limitam quanto possibilitam sua emergência. Como adverte Smolka (2004, p. 12), referenciada naqueles dois autores,

Os sentidos podem ser sempre vários, mas dadas certas condições, de produção, não podem ser quaisquer uns. Eles vão se produzindo nos entremeios, nas articulações das múltiplas sensibilidades, sensações, emoções e sentimentos dos sujeitos que se constituem como tais nas interações; vão se produzindo no jogo das condições, das experiências, das posições, das posturas e decisões desses sujeitos; vão se produzindo numa certa lógica de produção, coletivamente orientada, a partir de múltiplos sentidos já estabilizados, mas de outros que também vão se tornando possíveis.

Desse modo, cabe esta interrogação: que condições histórico-ideológicas ajudam a compreender por que os jovens elegem o discurso da prevenção pelo viés da normalização da conduta juvenil como principal meio de combate ao elevado consumo de drogas na contemporaneidade? Para tanto, a visada sobre os desenhos das ações públicas de saúde pode ser útil. Caponi (2009, p. 68) lembra que, tradicionalmente, as ações de saúde passaram ao largo dos questionamentos sobre os determinantes psicossociais dos processos de saúde/doença, incidindo principalmente nos indivíduos:

Diversas são as questões a serem consideradas com relação ao vínculo saúde-sociedade. Existem condições de vida impostas, convivência em um meio com determinadas características que não são nem poderiam ser escolhidas [...]Todas essas características constituem um conjunto de elementos que precisam ser considerados na hora de programar políticas públicas e intervenções com tendência a criar formas de transformação dessas desigualdades que reconhecemos como causas de predisposição para diferentes enfermidades. Até aqui a etiologia social da doença nos remete ao âmbito do público, e é nesse âmbito que deveriam delinear-se as estratégias de intervenção. Porém, existem estilos de vida escolhidos, eleições e condutas individuais pertencentes ao âmbito do privado que também consideramos como dados a serem explicitados quando falamos de 'etiologia social'. É preciso lembrar que a normalização das condutas e dos estilos de vida faz parte do próprio nascimento da medicina social. Desde o seu início, o âmbito do público e o âmbito do privado começaram a misturar suas fronteiras, fazendo com que as políticas de saúde se convertessem em intervenções, muitas vezes coercitivas, sobre a vida privada de sujeitos considerados 'promíscuos', 'alienados', ou simplesmente 'irresponsáveis'. [...] Tudo parece indicar que é mais simples normalizar condutas do que transformar condições perversas de existência. 
Portanto, a ideia de que o jovem é o principal responsável por sua entrada no mundo das drogas e a emergência de enunciados como Evite o primeiro gole! e É melhor prevenir do que remediar! são indícios de como o discurso proibicionista e moralizante, materializado pelo slogan Diga não às drogas!, era incorporado pelos participantes do grupo de discussão, orientando seus posicionamentos frente ao tema drogas.

Nas observações-participantes, foi possível conhecer iniciativas de alguns profissionais da escola, sobretudo um professor de história, através do que ele chamava de Grupo de Prevenção ao Uso de Drogas. Cartazes com informações sobre os danos causados pelo álcool e pelo tabaco, distribuição de panfletos, solicitação de trabalhos junto dos estudantes e realização de seminários em sala de aula enfocando essa temática: esses foram alguns exemplos de ações observadas no contexto daquela escola, todas elas aparentemente orientadas por um discurso proibicionista em relação ao assunto. Nas oficinas, os participantes mencionaram atividades realizadas na escola voltadas à prevenção do uso de drogas, frisando o grupo de prevenção ao uso de drogas formado pelo professor de história. Assim, passou-se a debater como os participantes percebiam a efetividade do que era realizado junto ao corpo discente da escola:

Pesquisador: Assim, vocês acham que esse tipo de atividade que é desenvolvida, ele é importante ou tem que ser desenvolvido outro tipo de atividade?

Renata: Assim, eu sou do grêmio, né, e a gente tá tentando montar um projeto de trazer palestras aqui pro colégio sobre drogas, alcoolismo.

Lia: Na minha opinião, tinha que fazer parte do cotidiano da gente, sempre, assim, três vezes na semana, pra nunca sair do foco do assunto. Se não, se fizer uma vez no mês, a pessoa esquece, num tá nem aí. Eu acho que é assim.

Laura: Assim, eu acho que quando a pessoa quer usar droga, ela sabe as consequências, ela sabe, usa porque ela quer. Porque a mídia fala, o colégio fala, mas a pessoa, num sei, ela tem uma ideia dela formada que pra ela ali é aquilo e pode falar o que você quiser, dizer o que quiser que a pessoa vai... igual na peça eu cheguei pra ela e falei 'não vai, não vai', ela foi do mesmo jeito. Então, eu acho que a pessoa vai porque quer, porque informação tem aí, você pode ir na internet e procurar, você pode ir num posto de saúde falar com assistente social, você pode ir na televisão, colégio, a informação tá aí, agora basta se você querer aceitar a acatar.

No episódio em exame, um embate de pontos de vista se evidencia: ao mesmo tempo em que surgem falas, como a de Lia, propondo a intensificação da abordagem já existente sobre drogas, a fim de que o segmento juvenil não esqueça das orientações, outras vozes - como a de Laura, no fim do episódio - evidenciam certa descrença quanto à efetividade dessas ações preventivas de caráter proibicionista. Isso torna a sugerir ambivalências dos posicionamentos dos adolescentes frente aos temas discutidos e frente às atividades de saúde já existentes, acarretadas pela coexistência de diversas vozes que vêm à tona através das atividades discursivas no contexto do grupo de discussão.

Educação \& Realidade, Porto Alegre, v. 40, n. 1, p. 253-273, jan./mar. 2015. 
A fim de discutir esses resultados, vale mencionar que, no âmbito internacional, um dos principais aspectos que marcaram o Setor Saúde foi a projeção da noção de promoção de saúde. Para Sícole e Nascimento (2003) e Buss (2009), um fato histórico para isso foi a elaboração, em 1974, do Informe Lalonde, que tecia críticas aos grandes custos dos cuidados à saúde e às suas limitações assistenciais. Diante disso, aquele relatório também sugeriu que o Setor Saúde alargasse sua intervenção mediante ações preventivas e educativas.

Outro ponto importante para impulsionar debates sobre promoção da saúde e estruturar o campo da Saúde Coletiva foi a Conferência Internacional sobre Atenção Primária de Saúde, ocorrida em 1978. Proveio desta conferência a Declaração de Alma-Ata, que fundamentaria questões relevantes como o direito à saúde, além dos lugares estratégicos do Estado e da atenção primária na organização do sistema de saúde (Nunes, 2006, p. 300).

Daquele período em diante, as concepções e práticas concernentes à promoção de saúde estiveram longe de formarem um bloco monolítico. Na linha do que escrevem Carvalho (2004) e Buss (2009), as várias conceituações disponíveis acerca da promoção da saúde podem ser agrupadas em dois grandes blocos.

No primeiro bloco,

[...] a promoção da saúde consiste nas atividades dirigidas à transformação dos comportamentos dos indivíduos, focando nos seus estilos de vida [...] Neste caso, os programas ou atividades de promoção da saúde tendem a se concentrar em componentes educativos primariamente relacionados com riscos comportamentais [...] (Buss, 2009, p. 22).

Aquelas intervenções ancoravam-se no pressuposto de que os indivíduos deveriam "[...] assumir a responsabilidade sobre os efeitos deletérios de seus hábitos de vida não saudáveis" (Carvalho, 2004, p. 670). Nesse bloco, promoção de saúde e prevenção de doenças são quase sinônimos. Também como parte dessa confusão conceitual e metodológica entre prevenção e promoção, tradicionalmente, a educação em saúde enfocou na transmissão de informações ou no desenvolvimento de habilidades e atitudes para ajudar os indivíduos a fazerem escolhas saudáveis com relação ao estilo de vida ou comportamento.

A partir dos resultados apresentados, é plausível depreender que essa perspectiva educativa em saúde, na qual promoção e prevenção se confundem, ainda encontra lugar no cotidiano escolar e, inclusive, nos processos de significação por vezes construídos pelos próprios estudantes. Porém, Souza e Monteiro (2011, p. 834) apontam para “[...] as limitações e insucesso da abordagem tradicional de negação total ao uso de drogas, conhecida como 'Guerra às Drogas'”. Segundo as autoras, as abordagens mais promissoras são as que enfocam a saúde como 
um todo, aproximando-se do conceito de promoção de saúde e consequentemente do conceito de escola promotora de saúde, ou seja, uma escola com políticas, procedimentos, atividades e estrutura que resultem na proteção e promoção à saúde dos membros da comunidade escolar. Dessa forma, o segundo bloco dentre as perspectivas de promoção de saúde, advindo principalmente a partir da década de 1980, passa a focalizar os determinantes gerais sobre as condições de saúde, sendo que suas atividades se voltariam mais ao coletivo de indivíduos e aos seus contextos. Assim, conforme aponta Pereira et al. (apud Sícole; Nascimento, 2003, p. 104),

O novo paradigma representa uma nova maneira de interpretar as necessidades e ações de saúde, não mais numa perspectiva unicamente biológica, mecanicista, individual, específica, mas numa perspectiva contextual, histórica, coletiva, ampla. Assim, de uma postura voltada para controlar os fatores de risco e comportamentos individuais, volta-se para eleger metas para a ação política para a saúde, direcionadas ao coletivo.

Três conferências internacionais a respeito do tema, ocorridas em Ottawa, em Adelaide e em Sundsval, nos anos de 1986, 1988 e 1991, respectivamente, foram fundamentais para consolidar as bases conceituais e políticas contemporâneas desse modo de entender a promoção da saúde (Buss, 2009). Na I Conferência Internacional sobre Promoção de Saúde, foi elaborada a Carta de Ottawa, documento considerado o "[...] marco fundante da promoção da saúde como campo institucional de prática e reflexão" (Fleury-Teixeira et al., 2008, p. 218).

A propósito, a Carta de Ottawa concebe a promoção de saúde como "[...] o processo de capacitação da comunidade para atuar na melhoria da sua qualidade de vida e saúde, incluindo uma maior participação no controle deste processo" (Brasil, 2002, p. 19). Aquele documento ainda preconiza cinco campos de ação para a promoção da saúde: 1) elaboração e implementação de políticas públicas saudáveis; 2) reforço da ação comunitária; 3) desenvolvimento de habilidades pessoais; 4) reorientação do sistema de saúde; 5) criação de ambientes favoráveis à saúde.

Assim sendo, é profícuo considerar, no trato da questão das drogas no contexto escolar, que a promoção de saúde possui definição mais ampla do que a prevenção, concernindo a estratégias e ações direcionadas não apenas para evitar doenças, mas para a produção da saúde como produção de vida.

Portanto, esse conceito de promoção de saúde, manifesto na Carta de Ottawa, vai de encontro ao enfoque nas ações voltadas à correção de comportamentos individuais, vistos, na perspectiva preventivista - a exemplo do que se observa em alguns episódios apresentados alhures - como os maiores responsáveis pela saúde. Pelo contrário, promover saúde não é senão fortalecer a capacidade individual e coletiva para 
lidar com a pluralidade dos aspectos envolvidos na produção de vida. Além disso, o referido conceito inclui diversas organizações como protagonistas de tais ações, como a escola (Buss, 2009).

A propósito, a aplicação dos princípios da Carta de Ottawa no âmbito escolar resultou no conceito de escola promotora de saúde - EPS. Tais escolas promotoras de saúde procuram dar conta da "[...] natureza integral da saúde, equidade de gênero, envolvimento de toda a comunidade escolar, processo decisório participativo, sustentabilidade, adaptação cultural e inclusão de medidas que ampliem habilidades cognitivas e sociais" (Moreira; Silveira; Andreoli, 2006, p. 811).

\section{Considerações Finais}

Os dados produzidos indicam que a presença daquelas temáticas no cotidiano investigado entrelaçava-se não só com as vivências pessoais daqueles jovens, mas também com a condição juvenil da contemporaneidade e com as pautas das práticas de saúde dirigidas àquele público, inclusive nas situações cotidianas da vida escolar. Por um lado, entre os próprios jovens, foi potente a circulação de sentidos que ligam a saúde ao signo da prevenção de cunho proibicionista. Por outro lado, a análise permitiu identificar reposicionamentos dos jovens em relação aos temas, na medida em que, por exemplo, foi possível reconhecer especificidades das vozes juvenis sobre o assunto drogas, soando como questionamento às corriqueiras práticas de saúde na escolar.

Na condição de espaço de tensão entre vozes e de negociação de sentidos e posições, os processos interacionais apresentavam múltiplas possibilidades. Em muitos momentos, constituíram-se vetores de reiteração de valores e práticas arraigados socioculturalmente. Já noutros, favoreceram a ressignificação de tais valores.

$\mathrm{Na}$ discussão dos resultados, foram trazidas críticas, presentes na literatura científica, ao viés preventivo com foco na abstinência, apontando suas limitações quanto ao diálogo com a condição juvenil. Tais críticas apontam, por seu turno, para a fecundidade do desenvolvimento de ações de promoção de saúde com toda a população escolar, sem qualquer forma de discriminação. Assim, os conceitos e ações de promoção de saúde poderiam ser trabalhados sem o risco de conferir conotações moralizantes às práticas educativas sobre o tema drogas, partindo do pressuposto de que cada sujeito deve erigir modos singulares de produzir saúde em seus modos de andar a vida.

Assim sendo, Aratangy (1998) sugere que é importante configurar espaços onde os jovens possam compartilhar experiências significativas em grupo. Nesse sentido, embora na pesquisa-intervenção não tenhamos como controlar as reverberações das narrativas de si e do Outro produzidas no contexto do grupo de discussão, avaliamos que o grupo de discussão foi útil para a criação de dispositivos de análise coletiva naquela escola, compatibilizando o aprofundamento de informações 
com a problematização do cotidiano. A propósito, as discussões oportunizadas pela pesquisa-intervenção contribuíram para que questões pouco discutidas, naquele contexto, sobre drogas viessem à tona. Igualmente, serviu para problematizar o que era concebido pelos adolescentes como algo natural, não só relativo aos sentidos sobre os temas, mas inclusive com relação às próprias ações educativas em saúde que lhes eram direcionadas, dentro e fora da escola.

Recebido em 14 de janeiro de 2014 Aprovado em 09 de outubro de 2014

\section{Referências}

AGUIAR, Kátia Farias; ROCHA, Marisa Lopes. Micropolítica e o Exercício da Pesquisa-intervenção: referências e dispositivos em análise. Psicologia: Ciência e Profissão, Brasília, v. 27, n. 4, p. 648-663, dez. 2007.

ARATANGY, Lídia Rosemberg. O Desafio da Prevenção. In: AQUINO, Júlio Groopa. (Org.). Drogas na Escola: alternativas teóricas e práticas. São Paulo: Summus Editorial, 1998. P. 9-18.

BAKHTIN, Mikail (V. N. Volochínov). Marxismo e Filosofia da Linguagem. 10. ed. São Paulo: HUCITEC, 2002.

BEMFAM. Sociedade Civil Bem-estar Familiar no Brasil. Pesquisa sobre Saúde Reprodutiva e Sexualidade do Jovem: Rio de Janeiro, Curitiba e Recife - 1989/90. Rio de Janeiro: BEMFAM, Centers for Disease Control and Prevention, 1992.

BRASIL. As Cartas da Promoção da Saúde. Brasília: Ministério da Saúde, 2002. BRASIL. Política Nacional sobre Drogas. Brasília: Ministério da Saúde, 2005.

BUSS, Paulo Marchiori. Uma Introdução ao Conceito de Promoção da Saúde. In: CZERESNIA, Dina; FREITAS, Carlos Machado (Org.). Promoção da Saúde: conceitos, reflexões, tendências. 2. ed. Rio de Janeiro: Editora Fiocruz, 2009. P. $19-42$.

CAPONI, Sandra. A Saúde como Abertura ao Risco. In: CZERESNIA, Dina; FREITAS, Carlos Machado (Org.). Promoção da Saúde: conceitos, reflexões, tendências. 2.ed. Rio de Janeiro: Editora Fiocruz, 2009. P. 59-82.

CARVALHO, Sérgio Resende. As Contradições da Promoção à Saúde em Relação à Produção de Sujeitos e a Mudança Social. Ciência \& Saúde Coletiva, Rio de Janeiro, ABRASCO, v. 9, n. 3, p. 669-678, jul./set. 2004.

COLAÇO, Veriana de Fátima Rodrigues. Processos Interacionais e a Construção de conhecimento e subjetividade de crianças. Psicologia. Reflexão e Crítica, Porto Alegre, v. 17 n. 3, p. 333-340, dez. 2004.

COLL, Cezar.; ONRUBIA, Jose. A Construção de Significados compartilhados em Sala de Aula: atividade conjunta e dispositivos semióticos no controle e no acompanhamento mútuo entre professor e alunos. In: COLL, Cezar; EDWARDS, Derek. Ensino, Aprendizagem e Discurso em Sala de Aula: aproximações ao estudo do discurso educacional. Porto Alegre: Artes Médicas, 1998. P. 75-106. COSTA, Maria de Fátima Vasconcelos. Identidade Étnico-racial nas Artes de Brincar. In: VASCONCELOS DA COSTA, Maria de Fátima; COLAÇO, Veriana de Fátima Rodrigues; BARROS DA COSTA, Nelson (Org.). Modos de Brincar, Lembra e Dizer: discursividade e subjetivação. Fortaleza: Edições UFC. 2007. P. 4058 .

Educação \& Realidade, Porto Alegre, v. 40, n. 1, p. 253-273, jan./mar. 2015

Disponível em: <http://www.ufrgs.br/edu_realidade> 
FLEURY-TEIXEIRA, Paulo et al. Autonomia como Categoria Central no Conceito de Promoção de Saúde. Ciência \& Saúde Coletiva, Rio de Janeiro, ABRASCO, v. 13, Sup. 2, p. 215-222, dez. 2008.

FREITAS, Maria Tereza de Assunção. Vygotsky e Bakhtin - psicologia e educação: um intertexto. São Paulo: Ática, 1996.

GÓES, Maria Cecília Rafael. A Abordagem Microgenética na Matriz Histórico-cultural: uma perspectiva para o estudo da constituição da subjetividade. Cadernos CEDES, n. 20, p. 9-25, abr. 2000.

LOURAU, René. Análise Institucional e Prática de Pesquisa. In: RODRIGUES, Heliana de Barros Conde (Org.). René Lourau na UERJ. Rio de Janeiro: UERJ, 1993. P. 71-114.

MENEZES, Jaileila Alves; ARCOVERDE, Lílian Rocha; LIBARDI, Suzana Santos. A Pesquisa-Intervenção com Adolescentes: oficina como contexto narrativo sobre igualdade e diferença. In: CASTRO, Lúcia Rabelo; BESSET, Vera Lopes (Org.). Pesquisa-Intervenção na Infância e Juventude. Rio de Janeiro: Trarepa/ FAPERJ, 2008. P. 205-223.

MOREIRA, Fernanda Gonçalves; SILVEIRA, Dartiu Xavier; ANDREOLI, Sérgio Baxter. Redução de Danos do uso Indevido de Drogas no Contexto da Escola Promotora de Saúde. Ciência e Saúde Coletiva, Rio de Janeiro, ABRASCO, v. 11, n. 3, p. 807-816, jul./set. 2006.

MÜLLER, Ana Cláudia; PAUL; Cátia Lúcia; SANTOS, Nair Iracema Silveira. Prevenção às Drogas nas Escolas: uma experiência pensada a partir dos modelos de atenção em saúde. Estudos de Psicologia, Campinas, PUC, v. 25, n. 4, p. 607-616, out./dez. 2008.

NUNES, Everaldo Duarte. Saúde Coletiva: uma história recente de um passado remoto. In: CAMPOS, Gastão Wagner et al. (Org.). Tratado de Saúde Coletiva. São Paulo; Rio de Janeiro: Hucitec; Fiocruz. 2006. P. 295-312.

PAULILO, Maria Ângela Silveira; JEOLÁS, Leila Solberger. Jovens, Drogas, Risco e Vulnerabilidade: aproximações teóricas. Serviço Social em Revista, Londrina, UEL, v. 3, n. 1, p. 39-60, jan./abr. 2000.

SÍCOLE, Juliana Lordelo; NASCIMENTO, Paulo Roberto. Promoção de Saúde: concepções, princípios e operacionalização. Interface - Comunicação, Saúde, Educação, Botucatu, UNESP, v. 7, n. 12, p. 101-22, fev. 2003.

SMOLKA, Ana Luiza Bustamante. Sobre Significação e Sentido: uma contribuição à proposta de rede de significações. In: ROSSETTI-FERREIRA, Maria Clotilde; AMORIM, Kátia Souza; SILVA, Ana Paula Silveira (Org.). Rede de Significações e o Estudo do Desenvolvimento Humano. Porto Alegre: Artes Medicas, 2004. P. 35-49.

SOARES, Cássia Baldini; JACOBI, Pedro Roberto. Adolescentes, Drogas e AIDS: avaliação de um programa de prevenção escolar. Cadernos de Pesquisa, São Paulo, Fundação Carlos Chagas, n. 109, p. 213-237, mar. 2000.

SOUZA, Kátia Mendes; MONTEIRO, Simone. A Abordagem de Redução de Danos em Espaços Educativos Não-Formais: um estudo qualitativo no estado do Rio de Janeiro, Brasil. Interface - Comunicação, Saúde, Educação, Botucatu, UNESP, v. 15, n. 38, p. 833-44, jul./set. 2011.

VIGOTSKI, Lev Seminovith. A Construção do Pensamento e da Linguagem. São Paulo: Martins Fontes, 2001. 
João Paulo Pereira Barros é professor do Departamento de Psicologia da Universidade Federal do Ceará (UFC). Psicólogo, mestre em psicologia e doutorando em educação brasileira pela Universidade Federal do Ceará (UFC). Especialista em Saúde Mental pela Universidade Estadual do Ceará (UECE).

E-mail: jppbarros@yahoo.com.br

Veriana de Fátima Rodrigues Colaço é doutora em Educação pela Universidade Federal do Rio Grande do Sul (UFRGS). Professora do Programa de Pós-Graduação em Psicologia da Universidade Federal do Ceará (UFC). Professora Colaboradora do Programa de Pós-Graduação em Educação Brasileira da UFC.

E-mail:verianac@uol.com 